\title{
Philosophiques
}

\section{In memoriam Raymond Klibansky}

Hommage à un grand maître

\section{Daniel Vanderveken}

Volume 33, numéro 2, automne 2006

URI : https://id.erudit.org/iderudit/013893ar

DOI : https://doi.org/10.7202/013893ar

Aller au sommaire du numéro

Éditeur(s)

Société de philosophie du Québec

ISSN

0316-2923 (imprimé)

1492-1391 (numérique)

Découvrir la revue

Citer ce document

Vanderveken, D. (2006). In memoriam Raymond Klibansky: hommage à un grand maître. Philosophiques, 33(2), 473-475. https://doi.org/10.7202/013893ar d'utilisation que vous pouvez consulter en ligne.

https://apropos.erudit.org/fr/usagers/politique-dutilisation/ 


\title{
In memoriam Raymond Klibansky. Hommage à un grand maître'
}

\author{
DANIEL VANDERVEKEN \\ Université du Québec à Trois-Rivières \\ Daniel_Vanderveken@UQTR.CA>
}

La mort récente ${ }^{2}$ de Raymond Klibansky, 99 ans, président honoraire de notre Institut international de philosophie, prive ce monde d'un maître penseur et acteur philosophique majeur de notre temps. J'éprouvais à son égard de l'amitié et, comme bien d'autres ici, une profonde admiration tant pour son œuvre philosophique et littéraire que pour ses actions et ses engagements exemplaires au cours de sa longue vie. Klibansky fut un véritable témoin du $\mathrm{XX}^{\mathrm{e}}$ siècle, dont il connut personnellement les grandes réussites culturelles et artistiques, ainsi que les terribles tourmentes et les désastres politiques et idéologiques. Il a fait face avec grand courage à la tyrannie et est devenu un véritable philosophe d'action. Toute sa vie, il s'est montré épris de vérité, de beauté et de justice. Soucieux de perfection, il croyait en la vertu du dialogue aussi bien pour le progrès philosophique que pour le rapprochement des hommes de bonne volonté. Les véritables dialogues mènent souvent à l'amitié. Sa vie le montre avec les amitiés qu'il a vécues aussi bien avec ses maîtres qu'avec ses collègues et étudiants. Quiconque a véritablement dialogué avec lui se rappellera toujours de son accueil, sa bienveillance, son intérêt pour des choses nouvelles, sa vivacité d'esprit, ses yeux bleus qui brillaient, son érudition et son génie ainsi que son don de mettre à l'aise tout en poussant plus loin la discussion.

Raymond Klibansky était professeur émérite des Universités de Heidelberg, Oxford et McGill. Il a connu au cours de sa vie de terribles infortunes. Mais il a aussi eu des chances inouïes ${ }^{3}$. Né à Paris de parents allemands, il lui faut quitter précipitamment la France lors du déclenchement de la première guerre mondiale. Jeune étudiant dans les années 1920, à l'Université de Heidelberg, soucieux de bien comprendre ce qu'est l'homme en commençant par le commencement, il se lance dans l'étude de la pensée philosophique et artistique grecque entouré d'incomparables savants et hommes de lettres allemands du temps comme Max Weber, Friedrich Gundolf et Ernst Curtius. Il est nommé Privatdozent à l'Université de Heidelberg et il est très vite reconnu internationalement pour ses travaux en histoire de la

1. Cet hommage a été lu aux Entretiens de l'Institut international de philosophie à Guernavaca, au Mexique, fin août 2005.

2. Raymond Klibansky est mort à Montréal, en son domicile, le vendredi 5 août 2005 .

3. Voir son livre Le philosophe et la mémoire du siècle. Entretiens avec Georges Leroux, Les éditions du Boréal, Montréal, 1998.

PHILOSOPHIQUES 33/2 - Automne 2006, p. 473-475 
philosophie et des idées. Il fréquente alors les plus grands et se lie notamment avec Karl Jaspers et Ernst Cassirer. D'origine juive, il est privé de l'accès à son bureau lors de la prise de pouvoir des nazis en 1933. Il a ainsi perdu, m'at-il dit, les résultats de longues années de recherche. Il est aussitôt directement menacé de mort à cause de ses travaux philosophiques. En découvrant dans les écrits latins de Maître Eckart l'influence de penseurs arabes et juifs, surtout de Maïmonide, Klibansky avait en effet contredit l'idéologie officielle nazie selon laquelle Maître Eckart était le premier grand philosophe proprement germanique. En outre, il s'était aussi insurgé contre les mesures et les méthodes nazies d'exclusion. Faisant immédiatement fuir les siens, Klibansky est cependant resté en Allemagne pour célébrer le deuxième anniversaire de la mort de son maître, Gundolf. C'est alors qu'il a convaincu les Warburg de fuir l'Allemagne avec leur précieuse bibliothèque. Réfugié ensuite en Angleterre, il apprit rapidement l'anglais et devint peu après Fellow à l'Université d'Oxford. Pendant la guerre, Klibansky a poursuivi son combat contre le fascisme. Il fut officier dans l'Intelligence service et fit profiter les alliés de ses connaissances historiques sur le bassin méditerranéen. Il a toujours regretté que les Américains n'aient pas pris en considération ses conseils de ne pas débarquer en Sicile. Toute l'histoire allait à l'encontre de ce débarquement.

Après la guerre, Klibansky est redevenu professeur à Oxford, puis est venu au Canada enseigner à l'Université McGill. Il a continué ses recherches en histoire de la philosophie. Il a beaucoup contribué, comme chacun d'entre nous le sait, au développement de l'Institut international de philosophie, à ses orientations, activités et publications. Il avait compris, avec sa terrible expérience du comportement de bien des Allemands pendant le régime nazi, la nécessité et même l'obligation de promouvoir l'esprit de tolérance et la liberté de pensée et d'expression à travers le monde, tout en respectant le pluralisme des langues et des cultures. À ce moment, des régimes communistes totalitaires survenus après l'occupation soviétique de l'Europe centrale et de l'est, mettaient à nouveau en danger réel les philosophes et intellectuels épris de liberté. Klibansky leur vint en aide de multiples façons. Il a soutenu et pratiquement aidé certains comme Gyorgy Lukaks, Leszek Kolakowski et Jan Patocka. Plusieurs ont même été sauvés grâce aux invitations qu'il a arrangées à l'Ouest. Il a aussi participé à de nombreuses protestations. Lors de l'invasion russe de la Tchécoslovaquie mettant fin au Printemps de Prague, c'est lui qui a inspiré la résolution de l'Institut, rappelant solennellement «que la liberté de pensée et d'expression est la condition indispensable de toute activité philosophique».

L'œuvre de Klibansky est immense. Il a contribué à l'histoire de la philosophie en commentant et en éditant les travaux de grands maîtres anciens comme Proclus, Nicolas de Cues et Maître Eckart. Rappelons ses livres, The Continuity of the Platonic Tradition ${ }^{4}$ et le Corpus Platonicum

4. The Continuity of the Platonic Tradition, The Warburg Institute, Londres, 1939. 
Medii Aevi ${ }^{5}$ Son livre avec Erwin Panofsky et Fritz Saxl Saturne et la mélancolie $e^{6}$ est un chef d'œuvre sur l'histoire de l'art et des idées. Il a en outre réussi à rapprocher les philosophes de différentes cultures et doctrines et à faire connaître leurs écrits en promouvant le dialogue et en dirigeant la publication de chroniques comme La philosophie au milieu du XX $X^{e}$ siècle , La philosophie contemporaine ${ }^{8}$, La philosophie en Europe et La philosophie d'expression française au Canada ${ }^{10}$. Il a aussi contribué à répandre l'idéal de tolérance en créant la collection "Philosophie et communauté mondiale », qui a publié des textes historiques fondamentaux en la matière comme de multiples traductions de la Lettre sur la tolérance, de John Locke, ainsi que la traduction anglaise des Édits d'Asoka ${ }^{11}$, l'empereur bouddhiste indien qui prêchait le respect de toutes les religions. Dans son dernier livre, Idées sans frontières, Klibansky fait une profonde analyse philosophique de la nature même de la tolérance :

Une tolérance sans limite est-elle possible ? Deux considérations s'imposent : il est clair que la tolérance ne s'étend pas à l'intolérance. D'une part, le respect du droit de l'Autre suppose que l'on ne tolère pas l'absence de respect. D'autre part, une tolérance sans limite, qui s'étendrait à l'incitation à la haine, par exemple, peut dégénérer en violence. De nos jours, la tolérance est de plus en plus liée au pluralisme: pluralisme des religions, des cultures, des langues ${ }^{12}$.

Voilà des phrases d'une grande actualité.

Je terminerai cet hommage en exprimant ma profonde gratitude à Éthel Groffier, l'épouse et précieuse collaboratrice de Raymond Klibansky, grâce à laquelle il a pu sereinement continuer son travail philosophique et son action éthique en faveur de la liberté jusqu'à la fin.

5. Corpus Platonicum Medii Aevi, Auspiciis Academiae Britannicae, edidit Raymondus Klibansky In aedibus Instituti Warburgiani, Londinii, Plato Latinus I, Meno, 1940 ; II, Phaedo, 1950 ; III, Platonis Parmedis nec non Procli Commentarium in Parmidem, 1953, Timaeus, 1962; Plato Arabus I, Galeni Compedium Timae Platonis, 1951; II, Alfarabius de Platonis Philosophia, 1943 ; III, Alfarabius Compendium Legum Platonis, 1952.

6. Saturn and Melancoly, Thomas Nelson \& Sons, LTD, Londres, New York, 1964.

7. La philosophie au milieu du XX $X^{v}$ siècle, 4 tomes, Florence, La Nuova Italia, 1958-59.

8. La philosophie contemporaine, 4 tomes, Florence, La Nuova Italia, 1968-1971.

9. La philosophie en Europe, sous la direction de R. Klibansky et D. Pears, Folio, Essais, Paris, 1993.

10. avec Josiane Boulad-Ayoub, La philosophie d'expression française au Canada: Le rayonnement du Québec, PUL, 1998

11. The Edicts of Asoka, traduits par N.A. Nickam \& R.P. McKeon, University of Chicago Press, 1959.

12. Idées sans frontières: Histoire et structure de l'Institut international de philosophie, avec Éthel Groffier, Paris, Les Belles Lettres, 2005, p. 123. 